\title{
Article \\ Immediate Notification of Traffic Accidents through a Mobile Application
}

\author{
Elizabeth Liñan Espinoza ${ }^{1}$, Erich Jordy Echevarria Carpio ${ }^{1}$ and Laberiano Andrade-Arenas ${ }^{1, *}$ \\ 1 Faculty of Sciences and Engineering,University of Sciences and Humanities; elilinane@uch.pe \\ eriechevarriac@uch.pe \\ * Correspondence: landrade@uch.edu.pe
}

\begin{abstract}
This research work deals with traffic accidents that are very concurrent in several countries, which in turn contribute to the mortality rate from 19 to 25 years of age and up. In the research work, immediate notifications for traffic accidents were carried out through a mobile application (app) where it will have an emergency button which will help the injured a lot, since the nearest help centers such as the police, fire brigades and the nearest hospitals, so that they can provide support to the people who suffered the accident. In the project, the implementation of Scrum Methodology was used since it served us an amount for the development of the prototypes of the App, and in turn with their roles it did not serve much help for the project, however, passers-by are of vital importance already that they will be the ones to make said report when observing a traffic accident and thus notify the nearest aid centers. As data collection for the creation of the software functions, a survey was carried out with more than 30 people, the functions applied in the application were programmed with the Dart language and generated under the flutter tool in order to be able to distribute it on different platforms such as Play Store and AppStore. The results obtained were the most anticipated since the application fulfills its function, thus reducing deaths and improving the speed of attention to traffic accidents and thus saving a life that is in danger.
\end{abstract}

Keywords: Accident traffic; app store; mobile app; mortality; notifications; scrum methodology.

\section{Introduction}

Traffic accidents have been one of the main contributors to the human death rate between the ages of 19 and 25 and over for decades. Many of the traffic accidents were not treated in time, taking patients to critical conditions and even causing death. Also mention that passersby are not always aware of all the help centers that are close to them, this causes them not to know where to call or alert when an accident occurs that requires immediate attention. According to the authors [1], proposes the development of a panic button to immediately alert the relatives of the injured person about these traffic accidents. Any passerby can use this tool to alert family members and help centers. The author mentions that this tool will contain all the patient's data, such as blood type, personal data, location, close relatives, among others.

The author [2], highlights the importance of understanding the kinematics of an accident. Kinematics is an analytical process of the scene of a vehicular accident to determine injuries that are likely to have been caused by forces and motion. This knowledge can be used to identify stable patients without alleged injuries that could still be at risk of suffering, later serious conditions due to the high intensity of the accident in which they were involved. This procedure also helps hospital healthcare professionals or paramedics to perform evaluations and identify injuries in cases where the anatomical and physiological principles of severity are not definitive.

Regarding the aforementioned, this research is started, starting the development of a mobile application capable of immediately notifying traffic accidents to the nearest centers according to the geographical location of the mobile device. The alert will be sent to aid 
centers such as the police, hospitals and firefighters, and thus those involved obtain the fastest attention from the nearest center. Any passerby can use this application on their mobile device and anyone can alert the centers.

The mobile application must be scalable and must be developed on multi-platform technologies to have a single code and this can be implemented in different operating systems. The mobile application must make use of cloud computing to reduce costs, have instant access to data and high scalability, thus allowing more clients to be connected and make their requests [3]. The information system must alert safely and reduce the margin of error so that doctors can make better documentation, thus keeping medical care running.

The objective of this research work is to ensure that this application can be used by any passer-by to be able to report traffic accidents to the nearest help centers and thus give immediate support to people who suffer accidents. Users will not need special permissions to use the application, nor will they have confidential information about patients. Another important aspect is that it is compatible with all current mobile devices and with any operating system.

The most important thing for the development of the mobile project is that can provide help to people who suffer a traffic accident, so that passers-by who use the App can provide immediate help to the injured. $y$ The most important thing about this project is to allow people to help other people to save many lives by giving them immediate help through the mobile application.

\section{Literature review}

The following research work will focus on the study of the immediate notification of traffic accidents through a mobile application in order to be able to provide help to people who occur or witness an accident and do not have an application or do not have emergency numbers at hand to help the injured, so they can notify the nearest health centers and be able to provide support to passersby and injured.

On the other hand, when it comes to car accidents, many are not prepared to provide first aid, for this reason he proposes a mobile tool that has a panic button to alert or notify the relatives of the injured in traffic [1], according to the author the application has the necessary information to allow any passerby to be the first to help in this situation, the methodology used is that of design science and as a final result according to the technology acceptance model, possible improvements to the application are presented.

In addition, the author [4] when an emergency happens, citizens can be very helpful to notify and provide support to people involved in an accident or crisis, since thanks to the evolution of current technology we are able to collect information quickly and easily in which it can be transmitted through different communication channels either with GPS, WiFi or cameras that can help in an emergency.

As is already known today, national and international governments have developed an emergency notification system in which you can obtain updated and accurate information from the beginning of the accident and in turn notify how many people were affected by the accident, in order to provide you with a better support for the victims.

In addition, the author [2], has developed several technology-based solutions to reduce traffic accidents during emergency response. For example, several vehicles now have an integrated system that detects crashes and notifies Emergency Management Systems (EMS) seconds after the incident. Automatic Accident Notification (ACN) systems built into some vehicles provide paramedics with information about an accident prior to their arrival at the scene. These systems are typically available in modern automobiles and are activated when the air bag is deployed (for example, the Ford SYNC 911 assist system) or the fuel pump emergency shutoff is activated. In some cases, the system is activated 
even without the deployment of an airbag, using sensors placed around the vehicle (for example, the GM On Star system). Some of these systems send a distress message to the police with the location of the victim when an accident is suspected. In some cases, car occupants are also connected by phone to emergency medical hot lines until help arrives.

Therefore, proposes to install an electronic device in the vehicle capable of detecting when the driver is unable to control the car, this device is also capable of sending text messages and obtaining the exact location using GPS When the device detects an accident, it sends SMS to the driver's family [5], the ambulance, the police and the pre-installed numbers of nearby hospitals.

According to the author [6], most people are very busy and have little rest, and this lack of rest is the reason why someone would be drowsy and indicates that more than 60 percent of adult drivers are drowsy. and a third have fallen asleep, for this reason it uses technology and implements an application capable of monitoring the person's heart rate, and if the heart rate falls below a certain range, alarms will be activated to wake up, The device to use is a watch with a heart rate sensor, the results of this means are that the watch will alert the driver and he will make the decision to continue or stop to rest.

Also the authors discuss how people used Twitter or Skype to share positions, texts and photos and to keep in touch with their families. One of Ichiguchi's most interesting findings was the impressive amount of information shared on Twitter that forced the Japanese government to open a specific account for this event and promote the use of predefined hashtags [4]. Consequently, to avoid connectivity problems, Wi-Fi hotspots in fast food restaurants, hotels, public infrastructures and even private flats were temporarily opened. In this way, citizens had the possibility to collect a large amount of information, which included not only text messages, but also photos, videos and GPS positions.

The author mentions [5], that with the help of the App it was possible to avoid an accident and prevent and thus save lives from danger. According to the author's information [6], this device will help reduce traffic accidents, and even before they occur, since it has sensors that prevent collisions or accidents.

Mention the author [7], that several studies found that human factors are the main reason for traffic accidents, with speeding being the main factor. In Tanzania, 74\% of accidents that occurred in 2010 were caused by human factors. Other factors include vehicle / mechanical and road conditions.

Likewise another of the authors talks about the literature review that has been conducted on the nature of road maintenance management perspective [8]. These reviews include road defects and knowledge of the mobile application and its implementation in the road maintenance and control management system.

This document aims to inform about the development of an Emergency Accident Alert mobile application to send an accurate alert and accident notification to the emergency call center [9].

The author [10], states that around 1.3 million people die each year and 50 million suffer a permanent disability due to traffic accidents and all these causes are related to unsafe driving. The application developed collects data during the trip and recognizes excessive speed and sudden acceleration, fuel consumption and sudden braking. By using this application, drivers learn to drive more safely. 
The author argues on a methodology and mobile application to monitor, analyze and recommendations of the driver based on behavior and prevent traffic accidents using a personal smartphone to be able to monitor the driver's behavior, phone cameras and built-in sensors such as Wifi, GPS and microphone are used, The methodology supports the following dangerous driver online states: distraction and drowsiness, as well as a dangerous offline state related to a high pulse rate [11], implement the system for Android smartphones.

Finally, in the entire review of the literature saw that several authors of several articles developed and implemented an app where it shows a help to the injured or that prevent traffic accidents and thus take care of the lives of others, since this way we can save a life and our application in which it was developed is for passers-by who witness an accident to notify the nearest help centers and thus they arrive immediately at the scene of the events in which the health specialists will help them.

\section{Materials and Methods}

In this episode, the implementation of the methodologies was carried out. The methodology that was implemented is the Scrum Methodology and at the same time we will have some technological tools that will help us develop the prototype of the mobile application that would come to notify traffic accidents through an emergency or alert button, to help the injured and also contact the nearest aid centers, since the most frequent reasons why these accidents occur are due to speeding, distraction and alcohol consumption.

\subsection{Scrum Methodology}

The Scrum Methodology is a software development model that helps to establish successful and organized projects step by step, Agility is what most characterizes the Scrum methodology [12], that is why it was chosen to implement it in the project.

The Scrum Methodology is the agile development of software that allows reducing the complexity of projects, also helping to make these projects more flexible, this method takes into account all the requested changes and quickly moves to the new requirements requested in the project. As we know, Scrum has very important roles [13], these roles are shown in Table 1.

Table 1. Scrum roles.

\begin{tabular}{cc}
\hline Role & \multicolumn{1}{c}{ Description } \\
\hline Product Owner & $\begin{array}{c}\text { This is the person who is in charge of } \\
\text { making decisions and will recognize } \\
\text { the business and the vision of the } \\
\text { client. }\end{array}$ \\
Scrum Master & $\begin{array}{c}\text { The person in charge of verifying } \\
\text { that the Scrum models and } \\
\text { methodology work. }\end{array}$ \\
Development team & $\begin{array}{l}\text { They are people who have the power } \\
\text { to organize themselves and take the } \\
\text { appropriate objectives to achieve a } \\
\text { common goal. }\end{array}$ \\
\hline
\end{tabular}

Scrum is a powerful management framework used in companies for organizing complex projects. Scrum methodology refers to an iterative process for managing product or software development. Scrum has, if diligently applied, several benefits: reduced costs, improved return on investment, fast results, delighted customers, more joy and confidence 
to succeed in a complex world[14].

In Figure 1, he processes of the Scrum methodology in which is the Product Backlog, the Sprint Backlog, the days of the Sprint processes and the increase in software work, in which the 3 Scrum roles that the Product Owner, the Development Team, the Scrum Master, the daily Scrum, the Sprint review and the retrospectives would do, are the ones that would help a lot in the development of the project [15].

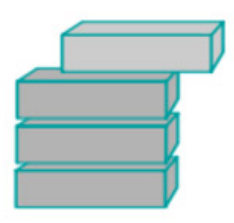

Product Backlog

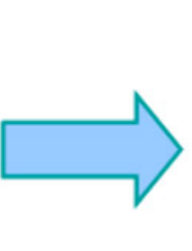

Sprint Backlog

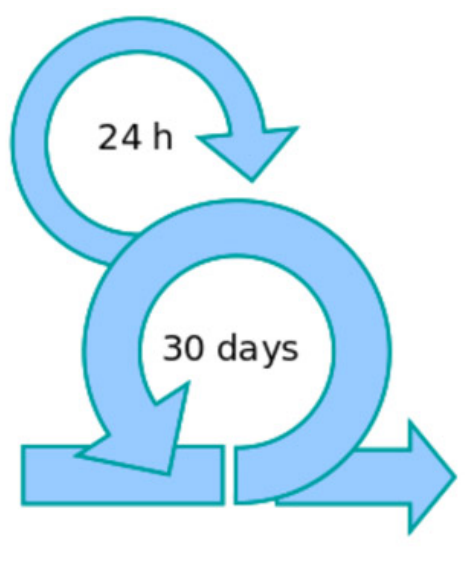

Sprint

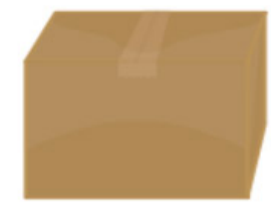

Working increment of the software

Figure 1. Methodology Agile Scrum..

\subsection{Process flow chart}

In this session the process of the flow diagram was carried out to alert the emergency centers, which the App will have your local location "GPS", and as seen in the image a brief description will be given.

In Figure 2, shows the processes that the passerby will carry out when witnessing a traffic accident, which has a beginning and an end, to help people who suffer an accident in which the process generates a GPS activation where the accident, which in turn when activating your location a traffic accident will be reported where a notification is sent to the nearest emergency centers.

As a start, the passerby must activate the location of his phone, once activated he verify if the location shown on the map is correct, if it is correct, the passerby will proceed to generate the notification to alert the emergency help in which he is focused on an accident. Once all this is done, the process will be completed and the emergency centers will arrive at the place where the accident occurred. 


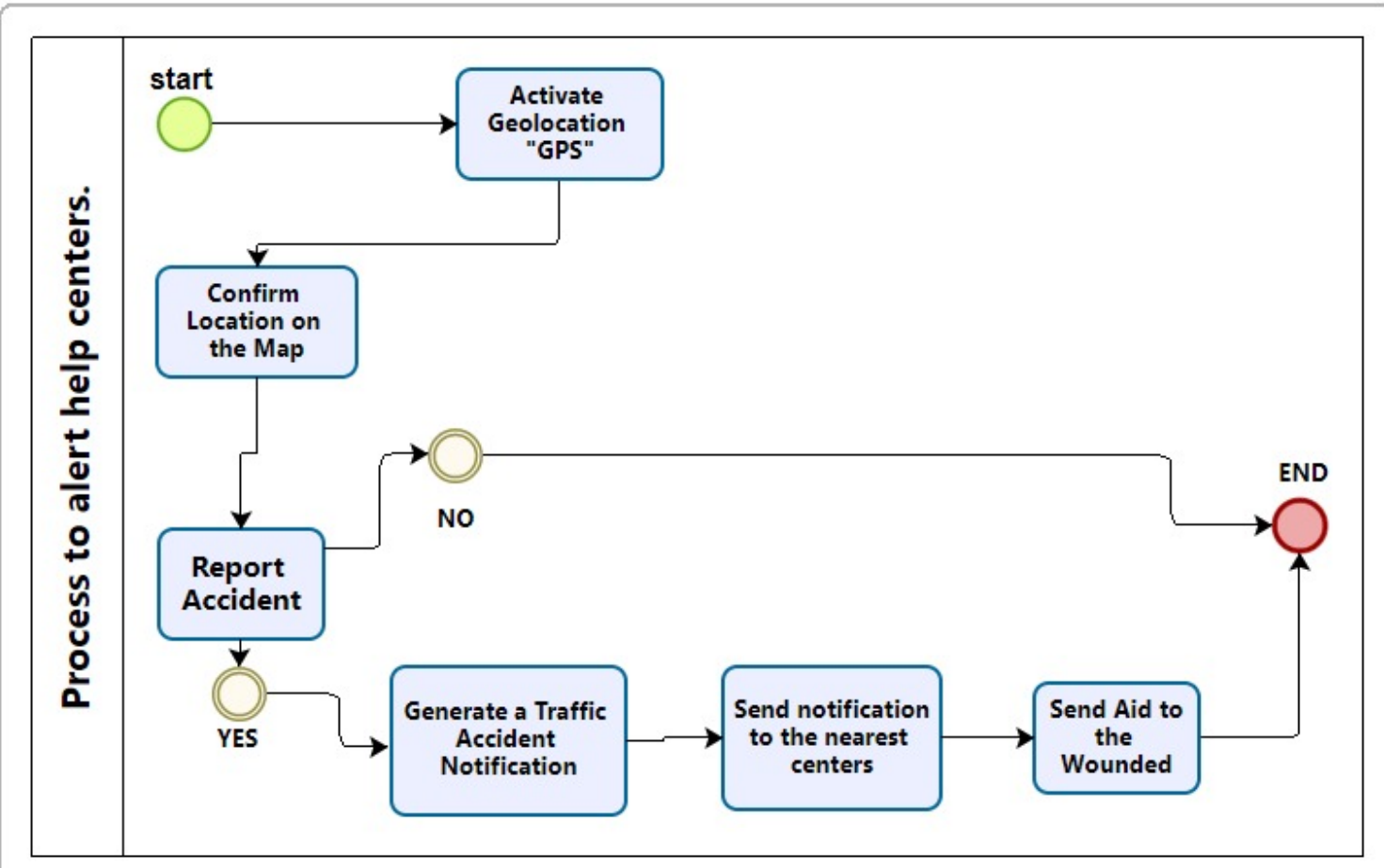

Figure 2. Flowchart to alert emergency centers.

\section{Case study}

In this section of the research, the development of the mobile application prototype was implemented and it was explained in detail, together with the aforementioned methodologies such as the Scrum Methodology and by Processes according to the requirements to have the prototype, next, the Sprint planning of each of the modules to be exercised and the estimation of the time used in each of the development stages was carried out and in turn the process of the planning Poker that would be carried out in the Product Backlog in which will count with the story points, etc.

\subsection{Sprint planning}

In the Sprint planning section was the specifications of the functions that the system will have and that in turn will increase the processes that was monitored, having already carried out the survey to a group of 30 people of different ages and from different provinces of Peru, it was possible to obtain different points of user stories, then the following formats that each User Story will have as I wanted and to be developed in the case was placed. The study of User history was shown in Table 2. 
Table 2. User story.

\begin{tabular}{|c|c|}
\hline Description & $\mathbf{N}^{\circ}$ \\
\hline $\begin{array}{c}\text { As a User, I want to log in through } \\
\text { Google. }\end{array}$ & 1 \\
\hline $\begin{array}{l}\text { As a User, I want information on } \\
\text { how to help the injured person. }\end{array}$ & 2 \\
\hline $\begin{array}{l}\text { As a User, I want the application to } \\
\text { allow attaching photos or videos to } \\
\text { confirm the accident. }\end{array}$ & 3 \\
\hline $\begin{array}{l}\text { As a User, I want to send the } \\
\text { real-time GPS location of the } \\
\text { accident site. }\end{array}$ & 4 \\
\hline $\begin{array}{l}\text { As a User, I want direct access to the } \\
\text { numbers of the centers to call them } \\
\text { immediately. }\end{array}$ & 5 \\
\hline $\begin{array}{l}\text { As a User, I want to have the location } \\
\text { in real time and be able to contact the } \\
\text { police or the nearby hospital. }\end{array}$ & 6 \\
\hline $\begin{array}{l}\text { As a User, I want the application to } \\
\text { be connected with the police and the } \\
\text { fire brigade. }\end{array}$ & 7 \\
\hline $\begin{array}{l}\text { As a User, I want you to } \\
\text { communicate directly to the police or } \\
911 .\end{array}$ & 8 \\
\hline $\begin{array}{l}\text { As a User, I want you to have direct } \\
\text { calls to the police, fire department } \\
\text { and ambulances. }\end{array}$ & 9 \\
\hline $\begin{array}{l}\text { As a User, I want to have a quick } \\
\text { access to alert about the accident. }\end{array}$ & 10 \\
\hline $\begin{array}{l}\text { As a User, I want you to have a map } \\
\text { with the points of the closest centers. }\end{array}$ & 11 \\
\hline
\end{tabular}

\subsection{Time estimation}

In the Time Estimation section, here the methods that was used in a more known and safe way, such as the Scrum Methodology, was shown, since Planing Poker was used in which its estimated time can be observed, the priority of the Sprint History and the history points, in which the History points add up to a total of 48 , and the estimate of the project had an approximate result of about 3 months, since they have user stories that were estimated between 1 and 3 weeks according to Table 3 . 
Table 3. User Story Process.

\begin{tabular}{|c|c|c|}
\hline Description & Priority & History Points \\
\hline $\begin{array}{c}\text { As a User, I want to log in } \\
\text { through Google. }\end{array}$ & 1 & 2 \\
\hline $\begin{array}{c}\text { As a User, I want information } \\
\text { on how to help the injured } \\
\text { person. }\end{array}$ & 3 & 4 \\
\hline $\begin{array}{l}\text { As a User, I want the } \\
\text { application to allow attaching } \\
\text { photos or videos to confirm } \\
\text { the accident. }\end{array}$ & 2 & 8 \\
\hline $\begin{array}{l}\text { As a User, I want to send the } \\
\text { real-time GPS location of the } \\
\text { accident site. }\end{array}$ & 1 & 4 \\
\hline $\begin{array}{l}\text { As a User, I want direct access } \\
\text { to the numbers of the centers } \\
\text { to call them immediately. }\end{array}$ & 5 & 2 \\
\hline $\begin{array}{l}\text { As a User, I want to have the } \\
\text { location in real time and be } \\
\text { able to contact the police or } \\
\text { the nearby hospital. }\end{array}$ & 2 & 6 \\
\hline $\begin{array}{l}\text { As a User, I want the } \\
\text { application to be connected } \\
\text { with the police and the fire } \\
\text { brigade. }\end{array}$ & 2 & 4 \\
\hline $\begin{array}{l}\text { As a User, I want you to } \\
\text { communicate directly to the } \\
\text { police or } 911 .\end{array}$ & 2 & 5 \\
\hline $\begin{array}{l}\text { As a User, I want you to have } \\
\text { direct calls to the police, fire } \\
\text { department and ambulances. }\end{array}$ & 4 & 4 \\
\hline $\begin{array}{l}\text { As a User, I want to have a } \\
\text { quick access to alert about the } \\
\text { accident. }\end{array}$ & 1 & 3 \\
\hline $\begin{array}{l}\text { As a User, I want you to have } \\
\text { a map with the points of the } \\
\text { closest centers. }\end{array}$ & 2 & 6 \\
\hline
\end{tabular}

\subsection{Planning poker}

It is a technique in which it has the purpose of calculating the estimates and most of the cases it is carried out to estimate the efforts made and thus elaborate the Sprint usury history, in Table 4 you can see the development processes of the User Stories, in which the interface and the duration are divided into two parts, in which it can be seen during the Sprint of the project to have the development of 3 Sprint and Its estimated time was from 1 week to 3 weeks according to the Product Backlog. 
Table 4. Product Backlog.

\begin{tabular}{ll}
\hline Interface & Duration \\
\hline Mobile application to report accidents to help centers. & 2 months y 2 weeks \\
Sprint 1: Login Interface. & 1 week \\
Sprint 1: registration interface. & 1 week \\
Sprint 1: main screen interface with alert button. & 1 week \\
Sprint 2: interface to take photos and record videos. & 3 weeks \\
Sprint 2: interface to upload videos and photos. & 2 weeks \\
Sprint 2: interface to upload videos and photos. & 2 weeks \\
Sprint 3: quick access interface to the alert. & 1 week \\
\hline
\end{tabular}

\subsection{Technological tools}

For the development of this mobile application, multiple programming languages such as Dart, JavaScript, php was used. The Flutter framework will also be used since it allows a single development to be carried out and distributed on different platforms such as "AppStore", "Play Store", "Microsoft Store". Third-party services such as signal will also be used, this service is used to make notifications to all mobile phones, including Huawei devices since these devices do not use Google services, finally, MySql is used as a database, and Marvel App was used to make all the designs.

\subsubsection{Dart Programming language}

It is a language created by Google and it is open source, its purpose is that it can be used in almost any project, Dart can be trans piled to JavaScript and thus be able to use it in web development, this code accompanied by a framework such as flutter allows developing applications multi platform mobiles.

\subsubsection{Database in MY SQL}

It is a database manager, it is well known and widely used for its high performance and ease of use.

\subsubsection{One Signal notification service}

It is one of the fastest and most reliable services to send notifications to all mobile phones in real time [16].

\subsubsection{PHP programming language}

It is a code that allows working both in back end and front end, php is an open source language and its purpose is aimed at web development, php runs on the server side and shows the client an HTML code, the client will never be able to see the php code running on the server [17].

\subsection{Application architecture}

In the architecture, users will be able to interact with the server through an API Rest, and third-party services will be required to be able to generate notifications in real time as shown in Figure 3, since the user will be the one who generates a notification, sending parameters to the server, which will generate the alert and record the event, the generated alert will immediately reach the nearest help centers using the geographic location of the passerby's phone as a reference. 

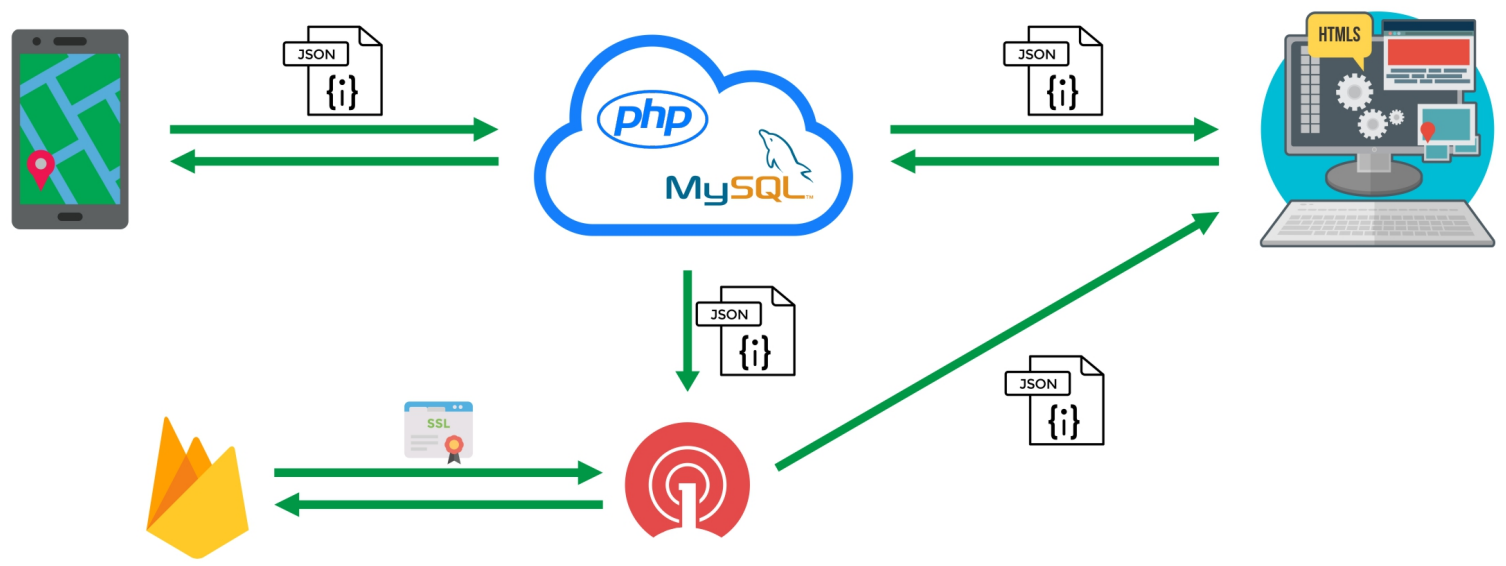

Figure 3. System architecture.

\subsection{Prototypes}

In this Section, the prototypes were developed in order to detect errors in the program, it was developed with the Marvel App tool, in which they were designed and implemented through User Stories, where this help users who use the App and thus have access to everything that the application provides.

\subsubsection{Development of Sprint 1}

In the Sprint 1 prototypes we have the Login screen in which in Figure 4 it can be seen that the user can log in with their google account or in which they will have to create or register an account to be able to access the application where It can be accessed to notify or send evidence of what happened in which its process was explained and how it will help the user.

In the other image that is the User Registration Screen, the User can have access by logging in with google, or they can also register if they do not have an account, they must complete their data, either their full names, their email where they are will send an access code, your phone number and your username and password.

it can be seen that in the development of Sprint 1 there was a screen to make an accident report through an emergency button where a notification was sent to the nearest help centers, so that health specialists. so that a life can be saved.

In the development of Sprint 1, an Emergent Help notification report is generated in which it is observed in Figure 5, this means that hospitals, clinics, Police and firefighters can reach the site where the accident occurred and thus provide help to the injured.

The user will be able to observe through the application that the report has already been taken either by a hospital, clinic, police or fire department where the user will be notified that help is on the way and thus the health specialists make their I work saving a life, and in turn the police will analyze how the accident occurred in order to lift the body.

\subsubsection{Development of Sprint 2}

In the development of the Sprint 2 prototype, it will have a screen in which the user who witnesses the accident can send evidence in the application so that patient care is faster and the necessary help arrives to save a life, since Thanks to the evidence, the Police, 


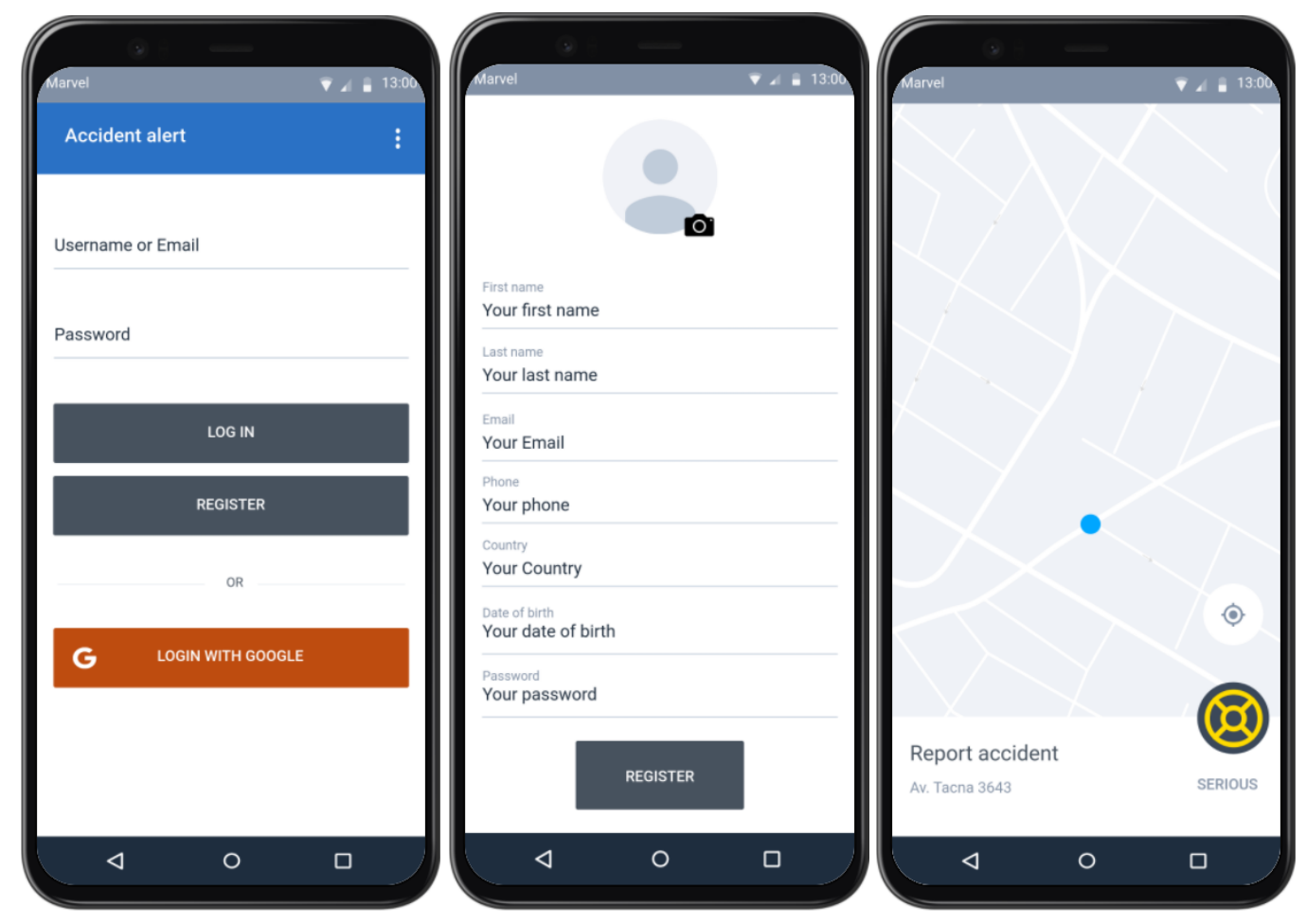

Figure 4. Login, User Registration and Report screen.

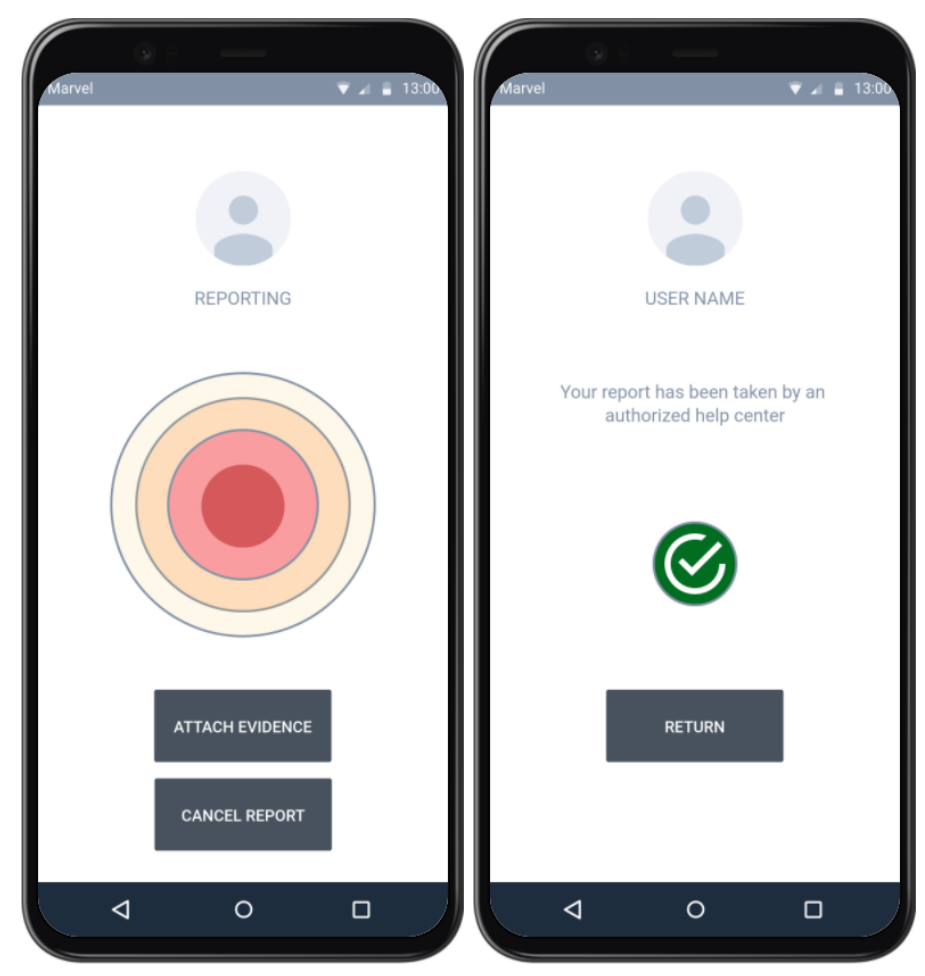

Figure 5. Report generation screen and Photo and Report screen taken. 
Firefighters and Doctors know what happened.

In the development of Sprint 2, as can be seen in Figure 6, we can see that the user will have access to take photos or videos in which they can upload to the application so that the help arrives faster and knows what happened with the injured person.

it can be observed that the user has access to take photos or to be able to record since they will have the permission of the camera and the audio so that they know what is happening and thus save a life.

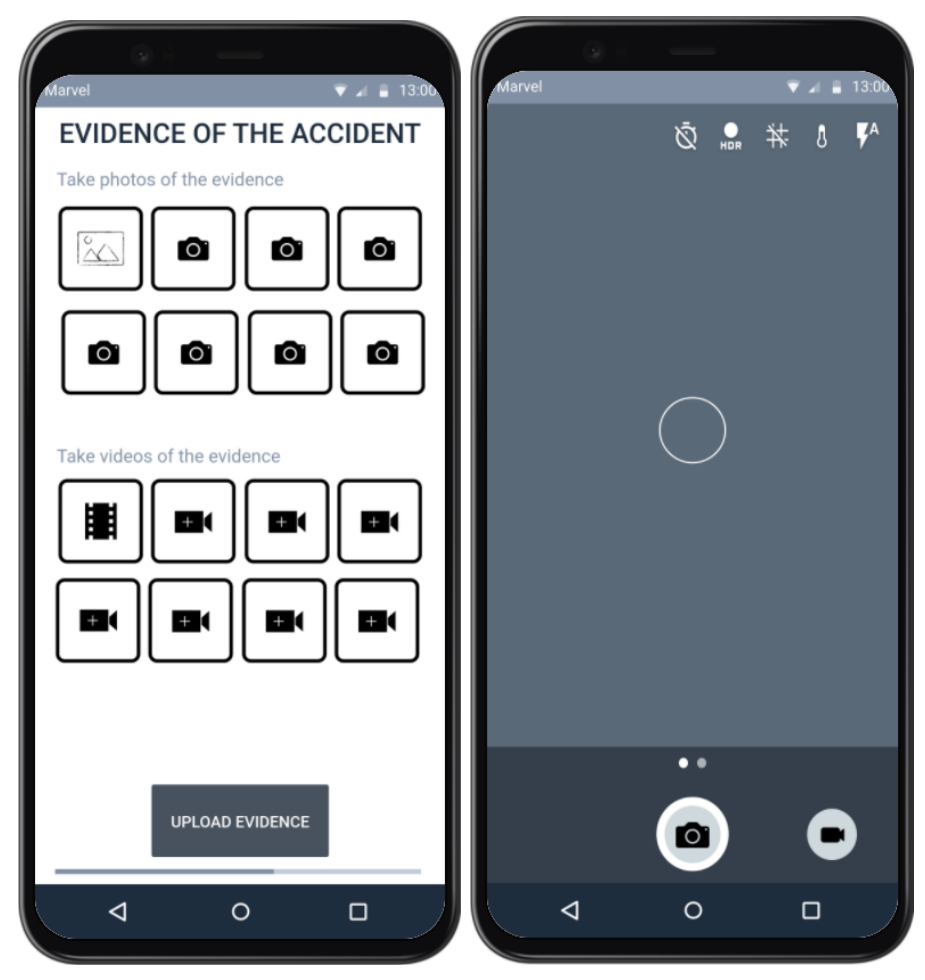

Figure 6. Evidence capture screen and upload them to the server and Photo and video capture screen.

\subsubsection{Development of Sprint 3}

In the development of Sprint 3, the Last Sprint and prototype would be carried out, where there was a list of numbers of the Emergency Centers where the user can have the help they need to support the injured, since Not all have emergency numbers and that is why some injured lose their lives quickly because the necessary help to save them does not arrive, the App will facilitate access to users so that it is faster and more effective to provide the necessary help, and in turn it is necessary to facilitate faster notification to the help centers, as this can save a life, and depending on the location of the user who notified or reported the help, the nearest help centers will help the injured and They will arrive immediately, in the present development some images was shown with their brief description.

In the development of the Sprint 3 prototype in Figure 7, it can be seen that the application will have a list of emergency numbers if the user or passerby who uses the Application and does not have the emergency numbers, the Application will provide a list of the emergency numbers where you can provide first aid to the injured and thus prevent an accident or save a life that is in danger. 
The user or passerby who made an accident report was notified to the cell phone that their report has already been attended and they have been helped.

Is necessary with health specialists, and thus the injured person is well with the help provided by the emergency centers and thus the user knows how the injured person is, if he or she is already better or is in critical condition.

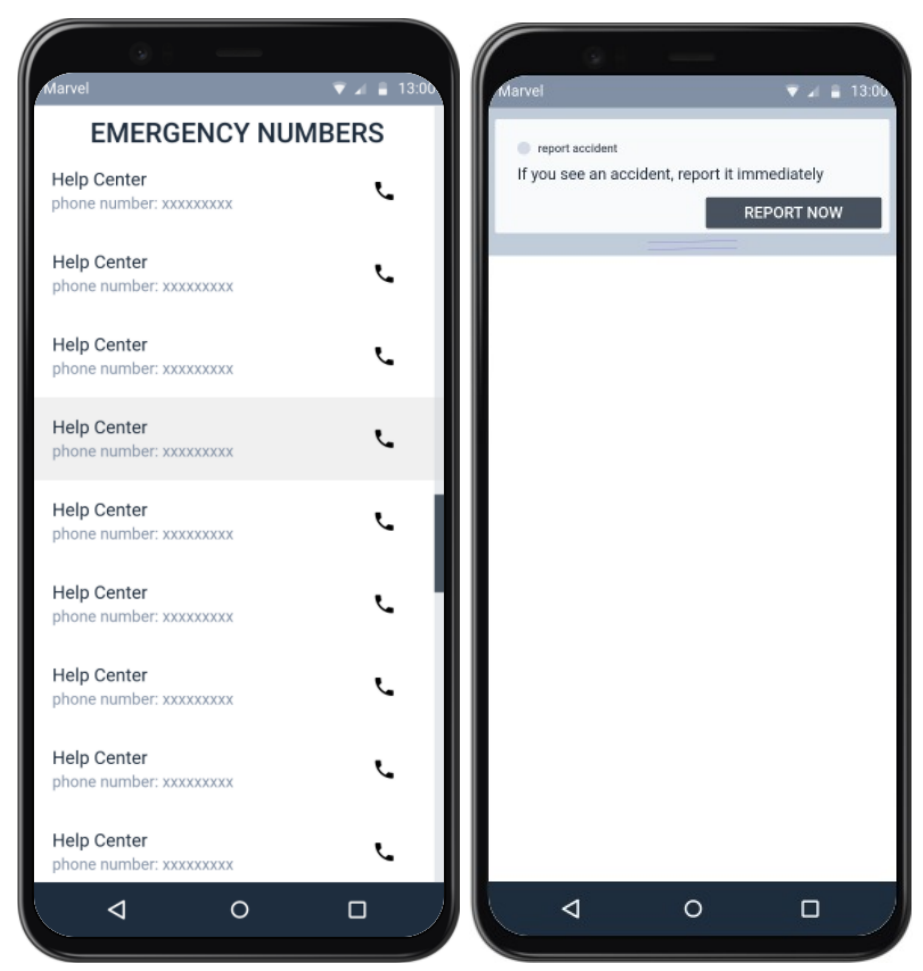

Figure 7. Emergency centers list screen and Quick access screen of the application.

\section{Results and Discussion}

In this episode the results of the prototypes of each of the user stories that were divided and grouped by the Sprint was shown, in which work have 3 Sprints, where the prototypes was analyzed, as well as discussions we will have the tests of the prototypes of the user stories, and at the same time of the acceptance that the prototypes would have, a survey was also carried out in order to implement it in the development of the project, a graph was also made showing the number of deaths and injuries that were caused for the accident.

\subsection{Survey Conducted}

A survey of 15 questions was carried out to a group of people in which they helped us a lot to carry out the sprints and user stories in which it was shown in the following images, thus showing which could be implemented in the development of The Sprint and what are the opinions of the users who would use the App in order to provide help to an injured or injured person.

Next, the following survey questions are presented and their respective percentage of acceptance of each question, as the first question is the following, when do you see an accident, would you like to help the injured? where $100 \%$ acceptance was obtained.

As a second question you have the following, would you use an application to help the injured? where $100 \%$ acceptance was obtained.

As a third question, there is the following, Allow your location to be sent to the help centers, to identify the place of the accident? where $100 \%$ acceptance was obtained. 
The fourth question is the following, Would you agree that the app allows you to send photos and videos to show the accident? where 100\% acceptance was obtained.

The fifth question is the following: Would you like to personally call the help centers or would you prefer that the app alert the nearest centers? where it was obtained that $88 \%$ prefer the app to do it.

As a sixth question, the following is asked: Do you think that an application would be a good option to help the injured? where $96 \%$ acceptance was obtained.

As the seventh question you have the following, do you think that the application should show all emergency numbers in a list? where $100 \%$ acceptance was obtained.

As the eighth question is the following, Would you agree that the application allows you to register with your social networks? where $100 \%$ acceptance was obtained.

As the ninth question is the following, Do you agree that you should not use the app to report accidents while driving? where $96 \%$ agreed.

As the tenth question is the following, When requesting help through the app, would you agree that the help centers can see your personal information such as names and surnames? where it was only obtained in $76 \%$ acceptance.

As the eleventh question you have the following, do you think it would be correct to show information about how you could help the injured person so that he can intervene if it is within his possibilities? where only $52 \%$ acceptance was obtained.

As the twelfth question you have the following, Would you feel uncomfortable if the app shows an advertisement at the end of an alert? where $56 \%$ acceptance was obtained.

As a thirteenth question, you have the following: Would you like to know the status of the injured that I help through the app? where $100 \%$ acceptance was obtained.

As the fourteenth question you have the following, What other functions would you like the app to have? where 25 suggested functions were obtained.

As the fifteenth question you have the following, should the application notify the help centers how? where the results shown in Figure 8, were obtained.

Should the app notify help centers how?

25 responses

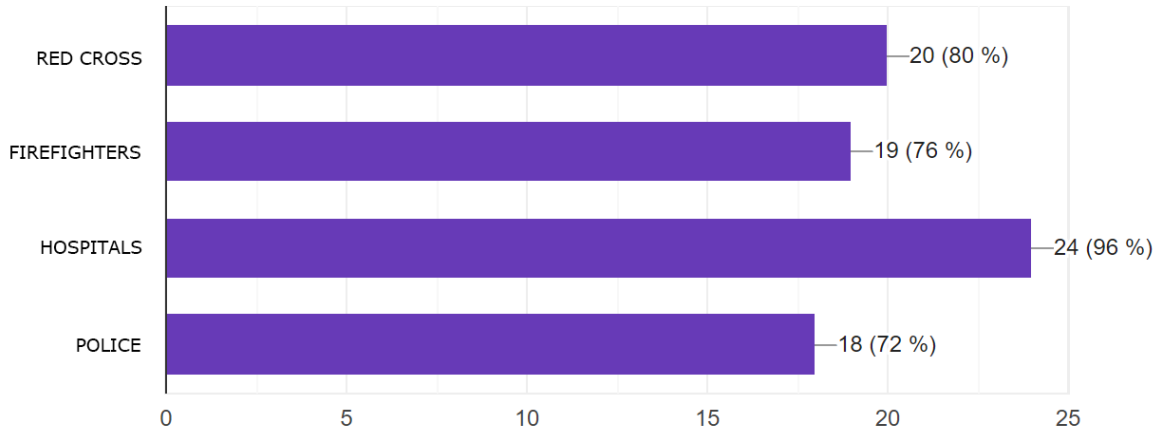

Figure 8. Notification Survey to Help Centers and Allow Access to the Location.

\subsection{Prototype analysis}

The prototypes were developed with the Marvel App tool in which it was designed with respect to the Sprint of User Stories, in the figures can see the design of the first Sprint that would come to do the Login, in the design it can be seen that the user can log in with his Gmail account through Google and in a very easy way, in the other figures see the design of the main screen of the application, in which the map, the position of the person and a button to report the accident are shown, in turn can observe.

In the analysis of the prototype, as can be seen in Figure 9, it was analyzed that the first and second prototypes of the user stories were super easy for user login and registration, 
since the user can access the Application through your Gmail email or create a new account so that you have access to the App.

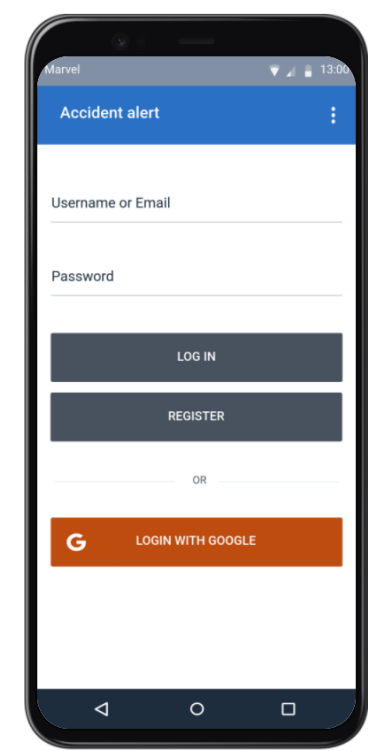

(a) HU-01

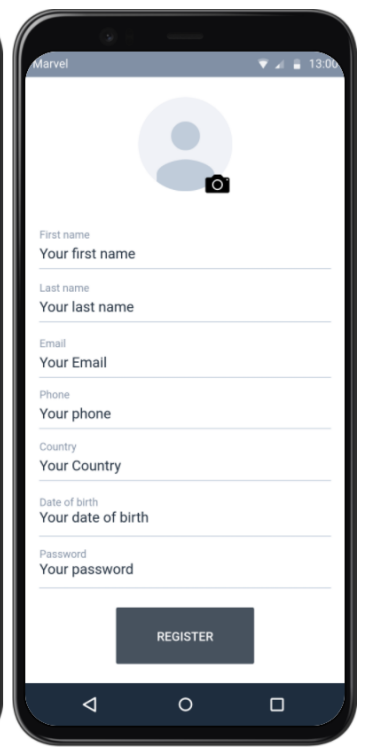

(b) HU-02

Figure 9. First and Second Prototype.

In the third and fourth prototype, as seen in Figure 10, it was analyzed that the user has access to report an accident through an emergency button, in which a report is made to the nearest help centers so that so help can be given to the wounded.

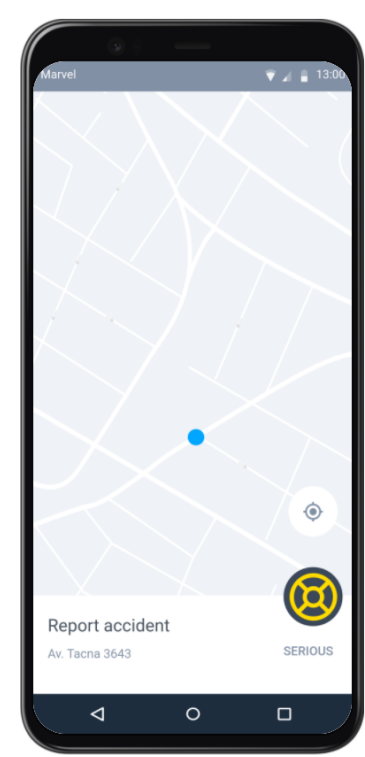

(a) $\mathrm{HU}-03$

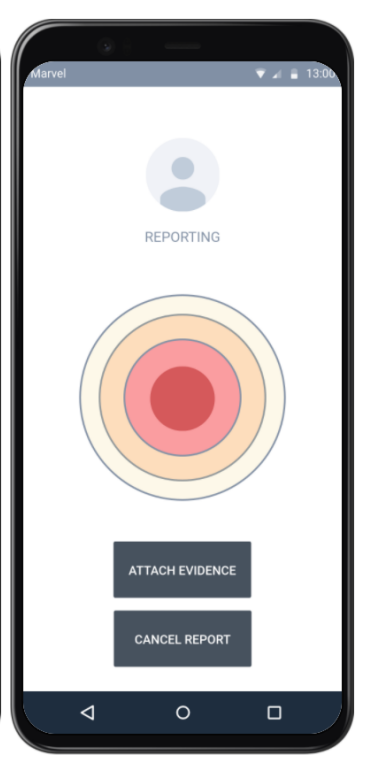

(b) HU-04

Figure 10. Third and Fourth Prototype.

In the fifth and sixth prototype, as seen in Figure 11, an analysis was reached that only the user can observe that his report is already being attended by specialized people, and in the sixth prototype it can also be observed that he has access to taking evidence of the accident. in which the user or passerby who uses the App may send evidence of the accident.

In the development of the seventh, eighth and last prototype, it can be seen that in Figure 12, it was analyzed that the user has access to the camera of his smartphone to take 


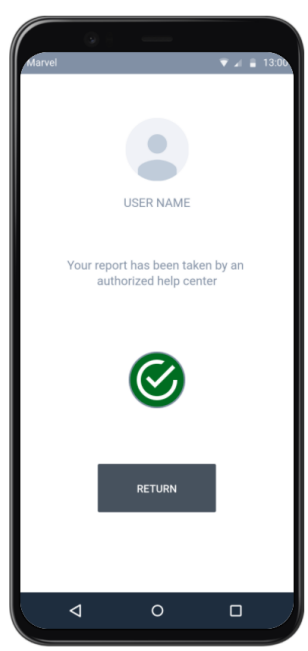

(a) HU-05

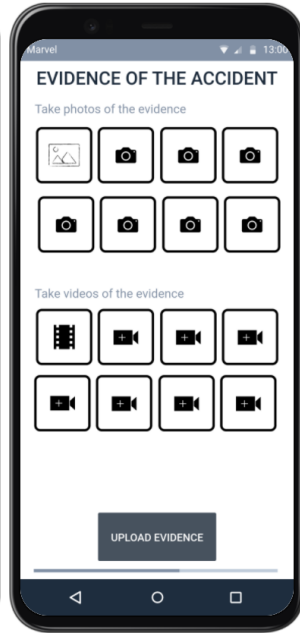

(b) HU-06

Figure 11. Fifth and Sixth Prototype.

evidence of the accident and in turn has a list of emergency numbers. so that the attention is faster and thus provide help to the injured, also in the last prototype you can see that a notification is sent to the user's cell phone, that his accident report has already been attended by a specialized center and in turn you can monitor how the injured person is doing.

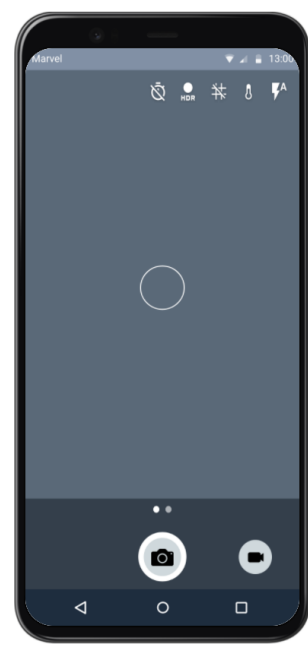

(a) HU-07

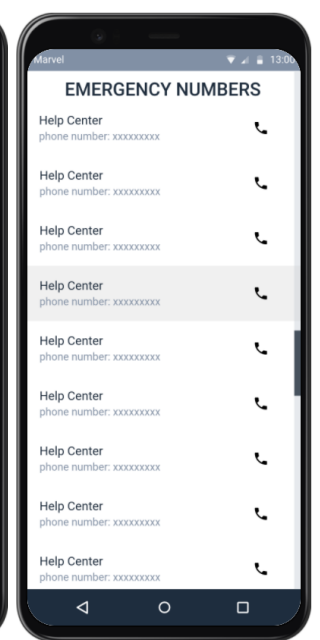

(b) $\mathrm{HU}-08$

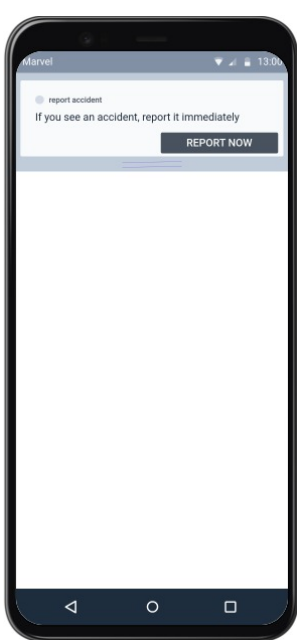

(c) HU-09

Figure 12. Seventh and Eighth Prototype.

\subsection{Analysis of traffic accidents in Peru}

In the Traffic Accident Analysis session in Peru, it can be known that for a long time one of the main causes of accidents is that people drive while intoxicated where they themselves harm and endanger their lives and the lives of others, that is why in Figure 13, can see a graph showing the numbers of deaths and injuries caused by traffic accidents, which greatly affects the population since family members suffer the loss of a loved one. 


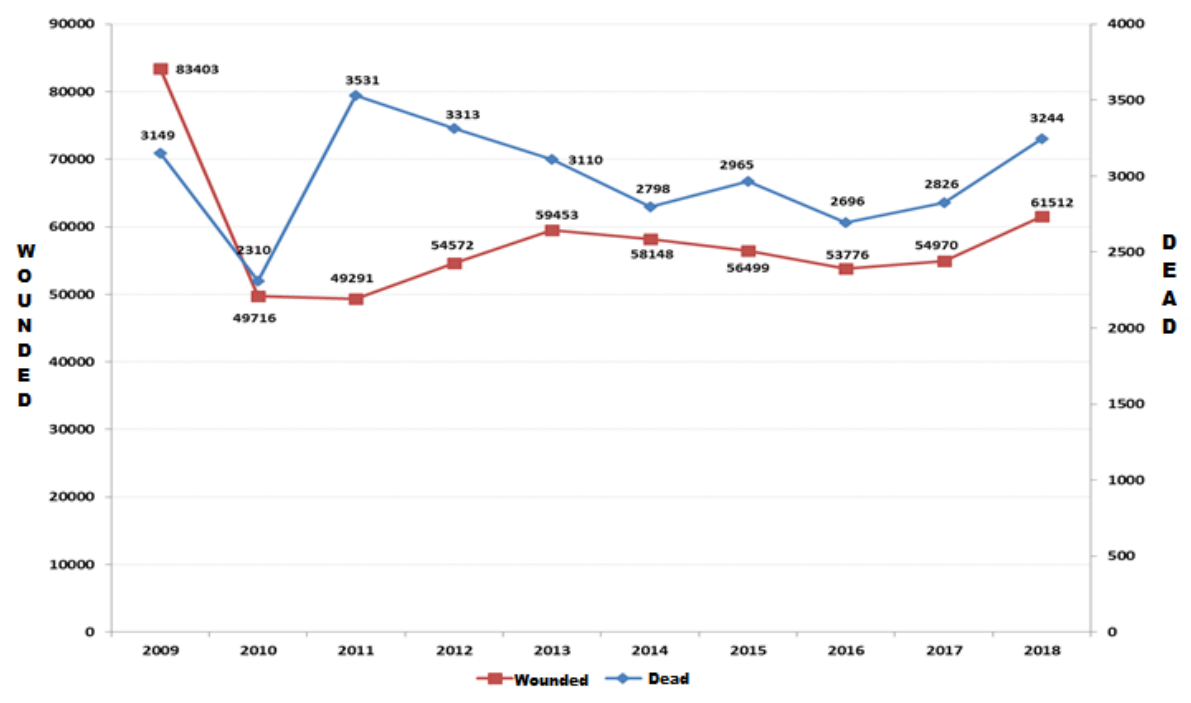

Figure 13. Traffic accident.

\subsection{Comparison of methodologies}

In this section, some methodological comparisons are made in which three methodologies was shown, such as the Scrum methodology, the Rup methodology and the cascade methodology, in which their objectives, their brief description and their stages was discussed as shown in the Table V.

Table 5. Method comparison.

\begin{tabular}{|c|c|c|}
\hline Scrum & Rup & Cascada \\
\hline $\begin{array}{l}\text { The Scrum methodology is a framework } \\
\text { that is used within teams that handle } \\
\text { complex projects. That is, it is an agile } \\
\text { work methodology that aims to deliver } \\
\text { value in short periods of time. }\end{array}$ & $\begin{array}{l}\text { The Rup Methodology provides a } \\
\text { disciplined approach to assigning tasks } \\
\text { and responsibilities within a } \\
\text { development organization. }\end{array}$ & $\begin{array}{c}\text { It is the model for Software development } \\
\text { that follows a logical sequence and each } \\
\text { stage is directly dependent on the } \\
\text { previous stage. }\end{array}$ \\
\hline In Types of Framework they have & In Types of Framework they have & The types of Framework such as Analysis, \\
\hline $\begin{array}{c}\text { Management and software development, } \\
\text { based on an iterative and incremental } \\
\text { process. }\end{array}$ & $\begin{array}{c}\text { Analysis, design, implementation and } \\
\text { documentation of object-oriented } \\
\text { systems. }\end{array}$ & $\begin{array}{l}\text { design, implementation, test and service } \\
\text { for the functionality of the systems for the } \\
\text { improvement of the software. }\end{array}$ \\
\hline $\begin{array}{l}\text { The Objectives of Scrum, indicated for } \\
\text { projects in complex environments are to } \\
\text { obtain prompt results, requirements, } \\
\text { fundamental innovation. }\end{array}$ & $\begin{array}{l}\text { The Objectives of the Rup Methodology } \\
\text { are object-oriented that establish the } \\
\text { bases, templates and examples for all } \\
\text { aspects and phases of software } \\
\text { development. }\end{array}$ & $\begin{array}{l}\text { The objective of the Cascada } \\
\text { methodology follows the old saying of } \\
\text { "measure twice, cut once". }\end{array}$ \\
\hline
\end{tabular}

\section{Conclusions}

In conclusion, each of these projects effectively benefits all drivers and passersby. These projects have positive results and help in one way or another so that the drivers and people who carry the application with them can be saved and rescued in the shortest possible time or before it happens and thus do not lose their lives, since the App provides a support for people, and at the same time an improvement to prevent traffic accidents and that there are no deaths thanks to the technology that now everyone can have, be it a modern cell phone, tablet, GPS and Wi-Fi. The research work gave good results reducing the lack of attention to the injured people, in this way the injured have been treated as soon as possible, thus reducing their entry into a critical state, and passers-by were the first to request help, since That is the purpose of the request for an emergency notification. The software developed can still be improved to optimize functions and add new functions 
in future versions and thus later become an App in which it provides support to all the people who use it. It is suggested that further research be carried out in order to implement artificial intelligence in future improvements.

Author Contributions: Introduction, E.L.E .; Prototypes, E.J.E.C.;Literature review , L.A.A. and E.L.E.;Resultados, E.L.E. and E.J.E.C.; analysis, L.A.A.; Methodology, E.L.E.; figure, E.J.E.C.; Table, E.L.E. and L.A.A.; writing-review and editing, E.J.E.C. and E.L.E.;translation; All authors have read and agreed to the published version of the manuscript.

Funding: This research received no external funding.

Institutional Review Board Statement: Not applicable.

Informed Consent Statement: Not applicable.

Data Availability Statement: In the article the data in this study are available in the corresponding author upon request. All data is not publicly available for privacy reasons.

Acknowledgments: The support of the University of Sciences and Humanities, through its research institute, is appreciated.

Conflicts of Interest: The authors declare no conflict of interest.

\section{References}

1. Wanumen, L.; Moreno, J.; Florez, H. Mobile based approach for accident reporting. Communications in Computer and Information Science, 2019, Vol. 895. doi:10.1007/978-3-030-05532-5_22.

2. Zualkernan, I.A.; Aloul, F.; Basheer, F.; Khera, G.; Srinivasan, S. Intelligent accident detection classification using mobile phones. International Conference on Information Networking 2018, 2018-Janua, 504-509. doi:10.1109/ICOIN.2018.8343170.

3. Hameed, S.A.; Nirabi, A.; Habaebi, M.H.; Haddad, A. Application of mobile cloud computing in emergency health care. Bulletin of Electrical Engineering and Informatics 2019, 8. doi:10.11591/eei.v8i3.1498.

4. Romano, M.; Onorati, T.; Aedo, I.; Diaz, P. Designing mobile applications for emergency response: Citizens acting as human sensors. Sensors (Switzerland) 2016, 16. doi:10.3390/s16030406.

5. Maturkar, D.P.; Dudhe, K.; Roy, K. Accident Identification and Alerting System. International Journal of Advanced Research in Science, Communication and Technology 2021, 5, 766-774. doi:10.48175/ijarsct-1331.

6. Burns, D. Mobile Appication Detector for Drowsy Drivers. PhD thesis, 2016.

7. Mrema, I.J.; Dida, M.A. A Survey of Road Accident Reporting and Driver's Behavior Awareness Systems: The Case of Tanzania. Engineering, Technology Applied Science Research 2020, 10. doi:10.48084/etasr.3449.

8. Jamail, N.H.M.; Abdul Halim, A.G.; Jamail, N.S.M. Development of intelligent road maintenance system mobile apps for a highway. Bulletin of Electrical Engineering and Informs 2020, 9. doi:10.11591/eei.v9i6.2489.

9. Sarlan, A.; Fatimah Wan Ahmad, W.; Ahmad, R.; Roslan, N. Emergency Accident Alert Mobile Application. Indian Journal of Science and Technology 2016, 9. doi:10.17485/ijst/2016/v9i34/100831.

10. Maulid, H.; Nurhidayat, W.; Priyono, S.J. SafeDri: A mobile-based application for safety driving. IOP Conference Series: Materials Science and Engineering 2020, 850. doi:10.1088/1757899X/850/1/012003.

11. Kashevnik, A.; Lashkov, I.; Gurtov, A. Methodology and Mobile Application for Driver Behavior Analysis and Accident Prevention. IEEE Transactions on Intelligent Transportation Systems 2020, 21. doi:10.1109/TITS.2019.2918328.

12. Carrion-Silva, A.; Diaz-Nunez, C.; Andrade-Arenas, L. Admission Exam Web Application Prototype for Blind People at the University of Sciences and Humanities. International Journal of Advanced Computer Science and Applications 2020, 11. doi:10.14569/IJACSA.2020.0111246.

13. Arias-Marreros, R.; Nalvarte-Dionisio, K.; Andrade-Arenas, L. Design of a Web System to Optimize the Logistics and Costing Processes of a Chocolate Manufacturing Company. International Journal of Advanced Computer Science and Applications 2021, 12. doi:10.14569/IJACSA.2021.0120897. 
14. Vogelzang, J.; Admiraal, W.F.; van Driel, J.H. Scrum methodology as an effective scaffold to promote students' learning and motivation in context-based secondary chemistry education. Eurasia Journal of Mathematics, Science and Technology Education, 15. doi:10.29333/ejmste/109941.

15. Gomero-Fanny, V.; Bengy, A.R.; Andrade-Arenas, L. Prototype of Web System for Organizations Dedicated to e-Commerce under the SCRUM Methodology. International Journal of Advanced Computer Science and Applications 2021, 12. doi:10.14569/IJACSA.2021.0120152.

16. Young, H.; Ortaldo, J. One-signal requirement for interferon-gamma production by human large granular lymphocytes. The Journal of Immunology 1987, 139, 724-727.

17. Hammoudeh, M.A.A.; Al-Ajlan, A.S. Implementing web services using PHP soap approach. International Journal of Interactive Mobile Technologies 2020, 14. doi:10.3991/ijim.v14i10.14391. 